\title{
Cosmetic outcomes of grafted tubularized incised plate urethroplasty in primary distal penile hypospadias: prospective comparative study with the classic Snodgrass repair
}

\author{
Shabib Ahmed ${ }^{1}$, Yasser A. Noureldin ${ }^{1,2^{*}} \mathbb{0}$, Hammoda Sherif $^{1}$, Ahmed Zahran ${ }^{1}$ and Rabea Omar ${ }^{1}$
}

\begin{abstract}
Background: To compare the outcomes between classic tubularized incised plate (C-TIP), known as Snodgrass urethroplasty, and grafted TIP (G-TIP) in the repair of primary distal penile hypospadias.

Methods: Parents of all children presented to our tertiary care institution with primary distal penile hypospadias were asked to participate in this study. Patients were equally randomized using closed envelope method into two groups; Group A underwent repair using G-TIP and Group B underwent repair using the C-TIP. Circumcised cases and/or cases with penile chordee $>30$ degrees were excluded from this study. Urethral catheter was kept for 7 to 10 days after surgery. The success rate and cosmetic outcomes assessed by HOSE score were evaluated at 6-month postoperatively.
\end{abstract}

Results: A total of 55 patients were recruited in each group. One hundred and seven patients of the 110 patients (54 and 53 in groups A and B, respectively) were evaluated at 6-month postoperatively using HOSE score. All preoperative data were comparable in both groups. Success was documented in 49/54 patients (90.7\%) in group A. The five failures were secondary to two cases of glans dehiscence and three cases of residual postoperative chordee. Whereas, success was documented in 48/53 patients (90.5\%) in group B. Complications were: a case of meatal stenosis, three cases of fistula, and a case of combined meatal stenosis and fistula. The HOSE score was comparable between the two groups $(15.4 \pm 1.09$ vs. $15.6 \pm 0.55 ; p=0.29)$. However, the operative time was statistically longer in the G-TIP compared with the C-TIP $(91.4 \pm 6.2$ min vs. $85.2 \pm 6.3$ min; $p<0.001)$, respectively.

Conclusion: The G-TIP urethroplasty provided comparable results with C-TIP in terms of cosmoses, success rate, and complications. However, G-TIP was accompanied with significantly longer operative time.

Keywords: Hypospadias, Repair, Cosmoses, Complications

\section{Background}

Tubularized incised plate (TIP) urethroplasty had been introduced by Snodgrass in 1994 for the repair of distal penile hypospadias [1]. Over time, this procedure has

\footnotetext{
*Correspondence: dryasser_noor@yahoo.com

${ }^{1}$ Department of Urology, Faculty of Medicine, Benha University, Benha 13511, Egypt

Full list of author information is available at the end of the article
}

become the surgical method of choice and increasingly popular because of its simplicity and favorable outcomes for repairing the distal, and some of the proximal penile hypospadias cases [2].

The most common complications after TIP urethroplasty are urethro-cutaneous fistula (UCF), meatal stenosis, and dehiscence. This was explained by the occurrence of inflammatory reaction and formation of granulation tissue at the urethral plate (UP) incision site where 
fibroblasts differentiate to fibromyoblasts and cause wound contraction until the surface is covered by urothelium. These complications have been found to occur more in cases with narrow urethral plate, shallow urethral groove, or small glans size [3].

In 2000, Kolon and Gonzales reported the technique of one-stage dorsal inlay inner preputial graft and reported its effectiveness for reducing the risk of meatal or neourethral complications in cases where hypospadias is accompanied with a flat or narrow glans, and this provided a vertical slit-like neourethral meatus at the glans tip [4]. However, few studies have reported on the cosmetic outcome of the G-TIP compared with the C-TIP.

In this study, we compared Kolon and Gonzales's grafted TIP (G-TIP) (known as grafted Snodgrass) technique with the classic TIP (Snodgrass) urethroplasty (C-TIP) in the outcome of repairing primary cases of distal penile hypospadias in terms of the cosmoses assessed by hypospadias objective scoring evaluation (HOSE) score [5]. The HOSE scoring system was devised and introduced by Holland and co-investigators and it included five observable variables (meatal shape and location, urinary stream, erection, and fistula), and it ranges from a minimum total score of 5 and a maximum total score of 16 [5].

\section{Methods}

\subsection{Study design and patient population}

Between January 2018 and July 2019, 110 children with primary distal hypospadias were prospectively recruited in this randomized study. The study protocol was approved by the local Research Ethics Committee in our tertiary care academic center. The technique and possible risks were explained thoroughly to the patients' sponsors according to the Declaration of Helsinki and its amendments. Circumcised cases or cases with penile chordee $>30$ degrees were excluded. Patients were equally randomized using closed envelope method into two groups (Group A using G-TIP urethroplasty technique and Group B using classic Snodgrass TIP urethroplasty) (Fig. 1).

\subsection{Operative details}

All procedures were performed under general anesthesia with caudal block. After preparing the genitalia and draping, traction suture was applied to the summit of the glans using $5 / 0$ polyglactin suture. Then Nelatone catheter passed into the hypospadiac meatus (size varied according to age of the patient, ranging from 6 to 8F).

In cases of G-TIP, the length and width of the graft were determined intraoperatively by the length and width of the incised urethral plate using sterilized paper of the suture envelope. The graft was harvested, defatted
(Fig. 2) and sutured by 7/0 Vicryl sutures to the edges and floor of the incised urethral plate (Fig. 3). Graft fenestration was done using $3 \mathrm{~cm}$ syringe needle.

In cases of C-TIP, repair was performed according to Snodgrass technique by creating circumferential incision below the corona with degloving of the penile skin. A U-shaped skin incision was made surrounding the meatus with two paramedian incisions made between glans and urethral plate. Degloving of the skin and dartos fascia to the root of the penis with tourniquet application in all cases. Dorsal plication of the corpora cavernosa was done using $5 / 0$ proline suture, when there is residual chordee not corrected after degloving. Dissection of the glanular wings from underlying corpora cavernosa to 3 o'clock on the left side and to 9 o'clock on the right side and to the end of the urethral plate. Deeply incising the urethral plate using Stevens tenotomy scissors, extending from the hypospadias opening to the end of the urethral plate distally, down to the tunica albuginea covering the underlying Corpus Cavernosus (Fig. 2).

In both groups, tubularization of the urethral plate was done over a Nelatone catheter of appropriate size, ranging from 6 to $10 \mathrm{~F}$ according to age of the patient and width of the incised urethral plate, in two layers; first continuous subcuticular 7/0 Vicryl sutures then second interrupted subcuticular 7/0 Vicryl sutures without tension. Distal end of the suture line was extended up to the mid glans. In cases where there was acceptably developed spongiosum, spongioplasty was performed. Neourethral suture line was covered with a dartos pedicled flap using button-hole technique then glanuloplasty and skin closure was attempted using Bayar's flaps. Urethral catheter was left in place for 7-10 days postoperatively. All cases were performed by three consultants who have experience in hypospadias surgery (SA; HS; RO).

\subsection{Postoperative protocol and follow-up}

Patients were discharged home on the day of surgery. Dressing was opened 5 days after surgery and the wound was left without dressing. In cases without wound complications as edema, ecchymosis or infection the catheter was removed after 7 days, however, the catheter was removed after 10 days if wound complications were encountered. Tobramycin (Eye ointment) was daily applied for the wound. A third-generation cephalosporin was given to all patients, with the dose calculated according to the age, until the urethral catheter was removed. Follow-up was regular at two weeks, and 1st, 3rd, and 6th months.

\subsection{Outcome assessment}

Cosmoses was assessed using HOSE score at the $6^{\text {th }}$ month postoperatively and was appraised by an 


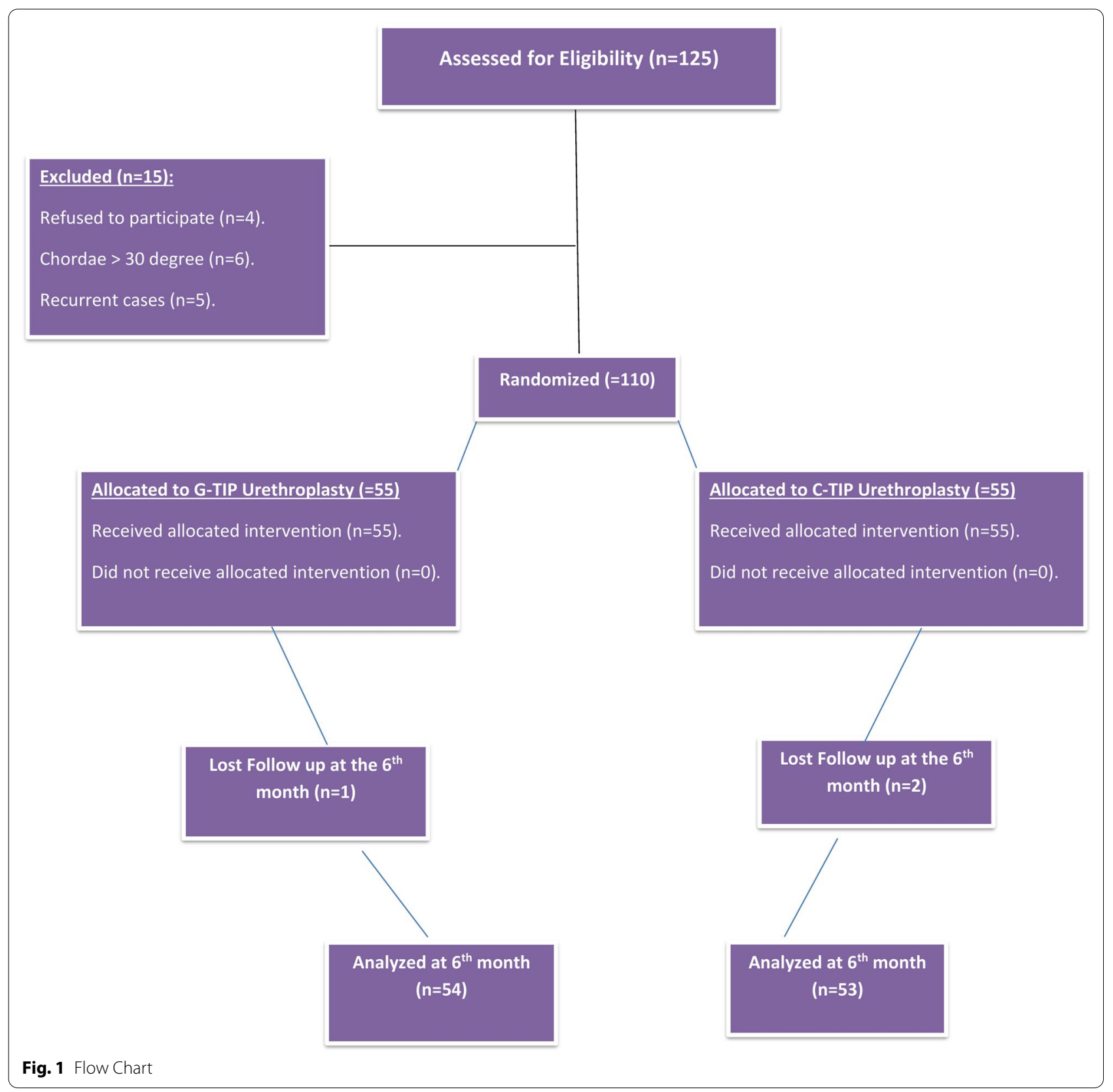

independent urological surgeon (AZ) and one of the parents, both were blinded to the operating surgeon. The assessment included all HOSE score parameters including meatal shape and location, urinary stream, erection, and UCF. The meatal location takes scores 1 to 4 based on whether it is distal glanular or proximal glanular or coronal or on the penile shaft; meatal shape takes score 1 to 2 based on whether it is vertical slit or circular; urinary stream takes score of 1 to 2 based on whether it is single stream or spray; erection takes score of 1 to 4 based on whether it is straight, mild or moderate or severe angulation; fistula takes score of 1 to 4 based on whether there is no fistula, single subcoronal, single proximal or multiple fistulae [5]. In all cases who developed early postoperative urethro-cutaneous fistula, a Nelatone $8 \mathrm{~F}$ urethral catheter and water-soluble sterile lubricant were used for daily meatal dilatation over a period of one month.

\subsection{Statistical analysis}

MedCalc software version 16.1@ 1993-2016 MedCalc Software, www.medcalc.org was used to calculate the 


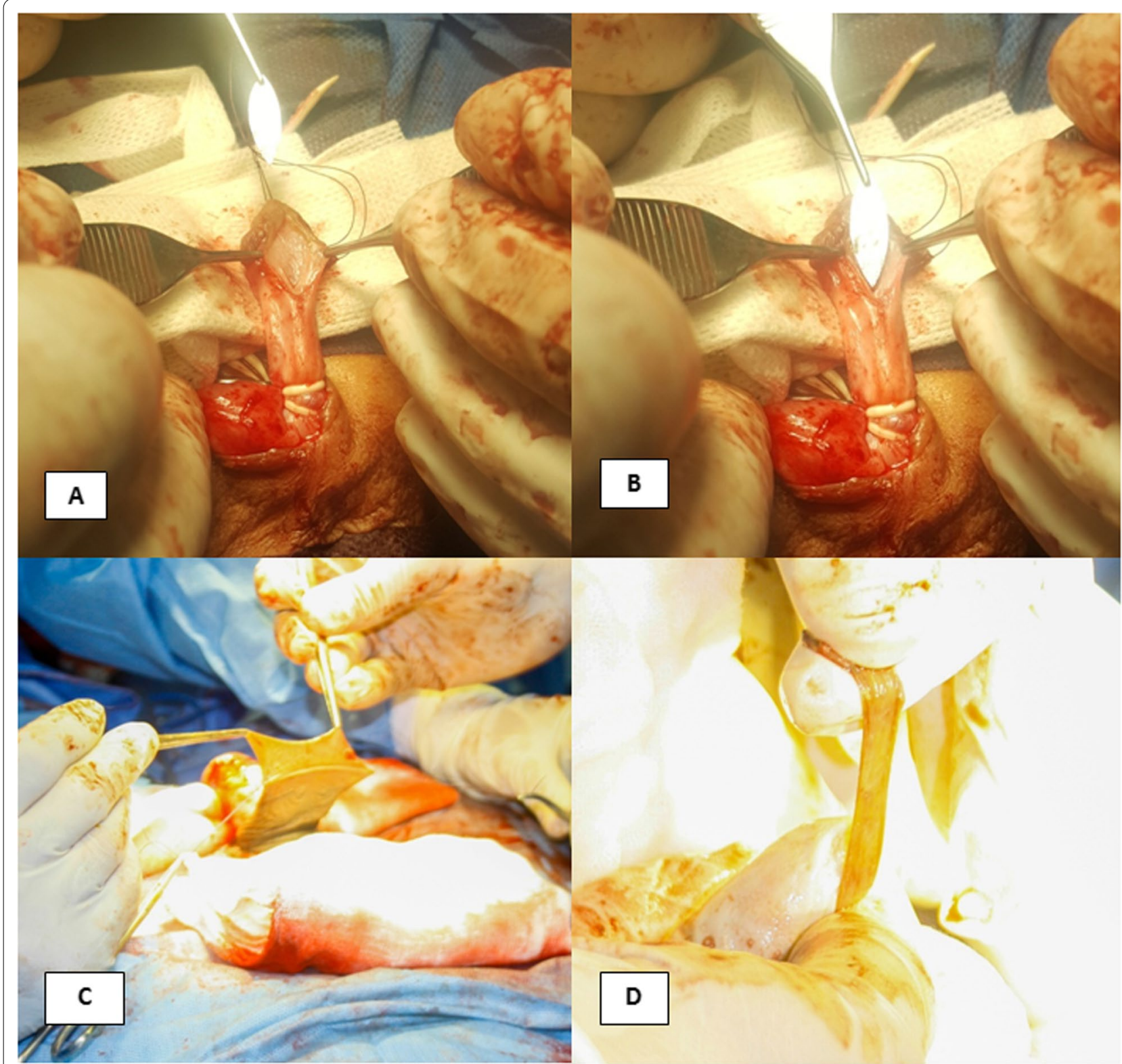

Fig. 2 a Deeply incising the urethral plate. $\mathbf{b}$ Apiece of sterilized paper (from the envelope of the vicryl suture) was used to nearly measure the length and width of the graft intraoperatively. $\mathbf{c}$ Harvesting skin graft from inner preputial skin. $\mathbf{d}$ Inner preputial skin graft harvested, defatted and ready to be inlayed

required sample size. The required sample was 53 subjects in each group and it was increased to 55 for more accuracy. The collected data were tabulated and analyzed using SPSS software version 20 from IBM. Categorical data were presented as numbers and percentages using Chi-square $(\chi 2)$ test or Fisher's exact test (FET) for analysis. Quantitative data were tested for normality using Shapiro-Wilks test and were presented as mean \pm standard deviation and range if normally distributed, median was added for non-parametric variables. Student's " $t$ " test was used to analyze parametric continuous variables among two independent groups, while Mann-Whitney $\mathrm{U}$ test was used for non-parametric ones, considering $\mathrm{p}$-value significant at $\leq 0.05$.

\section{Results}

Of 110 randomized patients, three patients (2.7\%) dropped out from the 6th-month assessment; one from group A and two from group B (Fig. 1). As regard preoperative data, the mean age was $33.6 \pm 39.4$ months in 


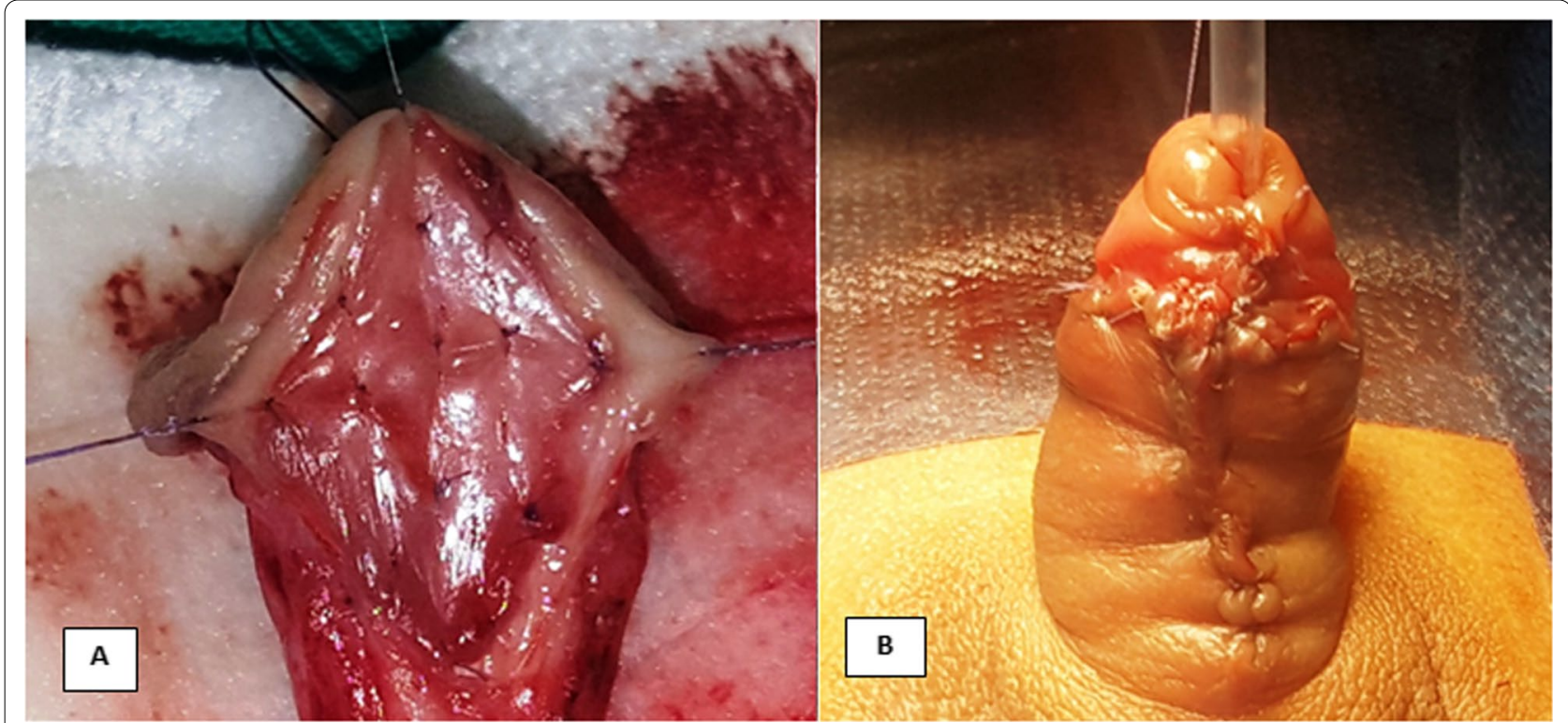

Fig. 3 a Inlaying the graft in the incised urethral plate and suturing the graft to the edges and the floor of the incised urethral plate using $7 / 0$ Vicryl sutures and Skin closure. b Final look following grafted Snodgrass repair

group A and $23.1 \pm 14.6$ months in group B $(p=0.24)$. Other Patients' characteristics and preoperative parameters in terms of associated anomalies, meatal caliber and location, presence of chordee $<30$ degrees, urethral plate length and width, and transverse glandular diameter were comparable and are depicted in Table 1.

Intraoperatively, the penis was degloved to the penoscrotal junction and artificial erection was made using a 23-gauge butterfly canula to assess for persistence of preoperative penile chordee. Eight cases were corrected after penile skin degloving (5 in group A and 3 in group $\mathrm{B} ; p=0.49)$ and 20 cases needed dorsal plication (9 in group $\mathrm{A}$ and 11 in group $\mathrm{B} ; p=0.68$ ). Spongioplasty was required in 29 cases in group A and 30 cases in Group B $(p=0.92)$. The operative time was statistically longer in the G-TIP compared with the C-TIP $(91.4 \pm 6.2 \mathrm{~min}$ vs. $85.2 \pm 6.3 \mathrm{~min} ; p<0.001)$, respectively.

After two weeks, there was no statistically significant difference between the two groups in terms of meatal location, meatal shape, and urinary stream

Table 1 Comparing the studied groups regarding pre- and intra-operative demographics

\begin{tabular}{|c|c|c|c|c|}
\hline \multicolumn{2}{|l|}{ Variable } & \multirow{2}{*}{$\begin{array}{l}\text { Group } A(N=55) \\
33.6 \pm 39.4\end{array}$} & \multirow{2}{*}{$\begin{array}{l}\text { Group B }(\boldsymbol{N}=\mathbf{5 5}) \\
23.1 \pm 14.6\end{array}$} & \multirow{2}{*}{$\begin{array}{r}\boldsymbol{p} \text {-value } \\
0.24\end{array}$} \\
\hline Age (months) (Mean \pm SD) & & & & \\
\hline \multirow[t]{3}{*}{ Associated anomalies No. (\%) } & None & $48(87.3)$ & $44(80.0)$ & 0.57 \\
\hline & Congenital hernia & $5(9.1)$ & $7(12.7)$ & \\
\hline & Undescended testes & $2(3.6)$ & $4(7.3)$ & \\
\hline \multirow[t]{2}{*}{ Meatus caliber No. (\%) } & Wide & $44(80.0)$ & $46(83.6)$ & 0.62 \\
\hline & Stenotic & $11(20.0)$ & $9(16.4)$ & \\
\hline \multirow[t]{3}{*}{ Meatus location No. (\%) } & Coronal & $4(7.3)$ & $7(12.7)$ & 0.20 \\
\hline & Subcoronal & $22(40.0)$ & $28(50.9)$ & \\
\hline & Distal penile & $29(52.7)$ & $20(36.4)$ & \\
\hline \multirow[t]{2}{*}{ Chordee No. (\%) } & No & $42(76.4)$ & $40(72.7)$ & 0.66 \\
\hline & Mild chordee & $13(23.6)$ & $15(27.3)$ & \\
\hline \multicolumn{2}{|c|}{ Transverse Glanular Diameter (TGD) (mm) (Mean \pm SD) } & $15.1 \pm 2.29$ & $14.5 \pm 1.43$ & 0.094 \\
\hline \multicolumn{2}{|c|}{ Urethral plate length (mm) (Mean \pm SD) } & $11.1 \pm 3.4$ & $10.0 \pm 2.29$ & 0.071 \\
\hline \multicolumn{2}{|c|}{ Urethral plate width (mm) (Mean \pm SD) } & $7.6 \pm 1.8$ & $8 \pm 0.96$ & 0.14 \\
\hline \multicolumn{2}{|l|}{ Operative time (min) (Mean \pm SD) } & $91.4 \pm 6.5$ & $85.2 \pm 6.3$ & $<0.001$ \\
\hline
\end{tabular}


( $p$-values $>0.05)$. A single subcoronal fistula was diagnosed in three patients in group A and seven patients in group $\mathrm{B}(p=0.32)$, and Glans dehiscence occurred in two cases of group A compared with no cases in Group B $(p=0.49)$. No cases were reported with wound infection, catheter slippage, skin sloughing, or fever.

At 6 months postoperatively, 107 of the 110 patients were evaluated. All data of meatal location, meatal shape, urinary stream, and erection were insignificantly different between the two groups (Tables 2, 3). However, single subcoronal fistula persisted in four patients in Group B (6 fistulae of the 10 which were found at 2 weeks assessment responded to frequent dilatation program and closed spontaneously, three in each group $(p=0.057)$. Regarding cosmetic assessment using HOSE score at the 6th month, the mean total HOSE score was 15.4 in G-TIP compared with 15.6 out of 16 in C-TIP $(p=0.29)$ (Table 2).
Success was documented in 49/54 patients (90.7\%) in Group A compared with 48/53 patients (90.5\%) in Group B $(p=0.99)$. The five failures in Group A were secondary to two cases of glans dehiscence and three cases of residual postoperative chordee, whereas it was due to one case of meatal stenosis, three cases of UCF, and a case of meatal stenosis and fistula in Group B.

\section{Discussion}

Classic TIP urethroplasty is considered the surgical method of choice for treatment for distal penile hypospadias because of its simplicity and favorable outcomes [6]. Distributed outcomes from patients who had undergone C-TIP urethroplasty for primary hypospadias repair has been outlined, and the mean overall complication rate was $10.8 \%$ (range, $0-33.3 \%$ ), with a mean rate of UCF of $5.7 \%$ (range, $0-21.2 \%$ ), a mean rate of meatal stenosis of

Table 2 Cosmetic assessment (HOSE score) at 6-month postoperatively

\begin{tabular}{|c|c|c|c|c|c|c|c|c|}
\hline \multirow[t]{2}{*}{ HOSE score parameter } & \multicolumn{3}{|c|}{ Group A $(N=54)$} & \multicolumn{3}{|c|}{ Group B $(N=53)$} & \multirow{2}{*}{$\begin{array}{l}\text { Student's " } t \text { " } \\
\text { test }\end{array}$} & \multirow[t]{2}{*}{$p$-value } \\
\hline & Mean & $\pm \mathrm{SD}$ & Range & Mean & $\pm \mathrm{SD}$ & Range & & \\
\hline Meatal location & 3.89 & 0.46 & $2-4$ & 4.0 & 0.0 & $4-4$ & 1.75 & 0.083 \\
\hline Meatal shape & 1.83 & 0.37 & $1-2$ & 1.86 & 0.34 & $1-2$ & 0.49 & 0.62 \\
\hline Urinary stream & 1.87 & 0.34 & $1-2$ & 1.90 & 0.29 & $1-2$ & 0.57 & 0.56 \\
\hline Erection & 3.89 & 0.46 & $2-4$ & 4.0 & 0.0 & $4-4$ & 1.75 & 0.083 \\
\hline Fistula & 4.00 & 0.00 & $4-4$ & 3.92 & 0.31 & $3-4$ & 1.89 & 0.061 \\
\hline Total HOSE score & 15.4 & 1.09 & $12-16$ & 15.6 & 0.55 & $14-16$ & 1.06 & 0.29 \\
\hline
\end{tabular}

* HOSE hypospadias objective scoring evaluation

Table 3 Descriptive data of the studied groups regarding frequencies of HOSE score parameters at the 6-month postoperatively

\begin{tabular}{|c|c|c|c|c|c|c|c|}
\hline \multirow[t]{2}{*}{ HOPE score } & & \multicolumn{2}{|c|}{ Group $A(N=54)$} & \multicolumn{2}{|c|}{ Group B $(N=53)$} & \multirow[t]{2}{*}{$x^{2}$} & \multirow[t]{2}{*}{$p$-value } \\
\hline & & No & $\%$ & No & $\%$ & & \\
\hline \multirow[t]{4}{*}{ Meatal location } & Distal granular & 52 & 94.4 & 53 & 100.0 & FET & 0.24 \\
\hline & Proximal glanular & 0 & 0.0 & 0 & 0.0 & & \\
\hline & Coronal & 2 & 5.6 & 0 & 0.0 & & \\
\hline & Penile shaft & 0 & 0.0 & 0 & 0.0 & & \\
\hline \multirow[t]{2}{*}{ Meatal shape } & Vertical slit & 45 & 83.3 & 46 & 86.8 & 0.25 & 0.61 \\
\hline & Circular & 9 & 16.7 & 7 & 13.2 & & \\
\hline \multirow[t]{2}{*}{ Urinary stream } & Single stream & 52 & 87.0 & 48 & 90.6 & 0.33 & 0.56 \\
\hline & Spray & 2 & 13.0 & 5 & 9.4 & & \\
\hline \multirow[t]{3}{*}{ Erection } & Straight & 51 & 94.4 & 53 & 100.0 & FET & 0.24 \\
\hline & Mild angulation & 3 & 5.6 & 0 & 0.0 & & \\
\hline & Moderate angulation & 0 & 0.0 & 0 & 0.0 & & \\
\hline \multirow[t]{4}{*}{ Fistula } & Non & 54 & 100.0 & 49 & 92.5 & FET & 0.057 \\
\hline & Single subcoronal & 0 & 0.0 & 4 & 7.5 & & \\
\hline & Single proximal & 0 & 0.0 & 0 & 0.0 & & \\
\hline & Multiple or Complex & 0 & 0.0 & 0 & 0.0 & & \\
\hline
\end{tabular}

\footnotetext{
* FET Fisher's exact test
} 
$4.7 \%$ (range, $0-19.0 \%$ ) and a mean rate of dehiscence of $1.3 \%$ (range, $0-4.2 \%$ ) [3].

Lopes et al., 2001 reported that the new dorsal urethral plate area could regenerate through normal epithelium, which is called re-epithelialization. They found that epithelial cells could move into the dorsal epithelial defect on postoperative day 2 , and the re-epithelialization process was completed by postoperative day 5 . These effects are thought to be helped by stenting the urethra in order to allow the urothelium to grow on a wider surface [7]. A urethral plate incision enables a urethral tubularization, but in cases with narrow urethral plate and shallow urethral groove, a scar tissue may form within the incised plate without epithelium, which can increase flow resistance and prompt to proximal fistula formation [8].

Intraoperative grafting of the raw surface of the UP was thought to prevent stricture by offering immediate coverage of the UP, stopping the granulation phase and the contraction [9]. In 2000, Kolon and Gonzales reported the technique of one-stage dorsal inlay inner preputial graft. The workgroup performed this technique in 32 patients, and at 21 months of follow-up, none of the patients had neourethral stricture, meatal stenosis, UCF, or urethral diverticulum. The authors reported that this technique creates a vertical slit-like neourethral meatus and it was effective in reducing the risk of meatal or neourethral complications in cases of a hypospadiac penis with a flat or narrow glans [4]. In 2018, Abbas and Pippi salle supposed that a ratio of the urethra before and after incision of $<0.5$ indicates that a significant component of the neourethra will be composed by raw tissue, and therefore the neourethra is vulnerable to stenosis, thus should be grafted [10].

Several studies reported on the efficacy of the G-TIP technique. Asanuma and colleagues studied dorsal inlay graft urethroplasty in 28 patients; 19 distal penile, six proximal penile, and six were penoscrotal [11]. Mouravas et al., and Gupta et al., recruited primary cases of hypospadias ranging from glanular to proximal and operated on them using G-TIP procedure $[12,13]$. Shuzhu et al., studied 508 cases of primary distal penile hypospadias, with the cases with poor UP were designated for the G-TIP technique (either inner preputial graft or buccal mucosa) and the cases with good UP were designated for the C-TIP repair [6]. Helmy et al., included 60 patients of primary distal hypospadias in a comparative study between C-TIP and G-TIP techniques with comparable preoperative data as regard to patients' age, meatus location, UP length and width and depth, and glans width [14].

In the current study, we analyzed the results of G-TIP versus C-TIP in 107 cases of primary distal hypospadias with comparable success rates and cosmesis. However, the operative time with statistically longer in the G-TIP $(91.4 \pm 6.2$ vs. $85.2 \pm 6.3 \mathrm{~min}(\mathrm{p}<0.001)$. This was congruent with the findings of Asanuma et al. study, where the operative time was 200 min including an additional time needed for the dorsal inlay graft of approximately $40 \mathrm{~min}$ [11]. Similarly, Helmy et al. study reported longer operative time in the G-TIP $(106 \pm 12 \mathrm{~min})$ compared with the C-TIP (79 $\pm 9 \mathrm{~min})(p=0.005)$ [14].

In the current study, meatal stenosis was not reported in the G-TIP group and occurred in two cases $(3.7 \%)$ of C-TIP, one of these was associated with UCF. In Mouravas et al. study, $17.4 \%$ of the cases in the C-TIP developed meatal stenosis compared with no cases in the G-TIP group [12]. Similarly, Gupta et al. reported no cases with meatal stenosis in their study [13]. Moreover, Shuzhu et al., reported $3 \%(6 / 198)$ meatal stenosis in the C-TIP group compared with $4.4 \%(7 / 160)$ in the G-TIP group [6], and Helmy and colleagues reported 3.3\% meatal stenosis in C-TIP group compared with no cases in G-TIP group [14]. However, most of the studies did not show statistically significant difference between the G-TIP and $\mathrm{C}$-TIP in terms of meatal stenosis, yet the results showed potentially better results in favor of the G-TIP.

In this study, ten cases of UCF occurred (3 in the G-TIP and 7 in the C-TIP) early in the postoperative course at 2 weeks. Regular urethral dilatation was done for all cases for one month where spontaneous healing occurred in all cases of G-TIP and three cases of C-TIP. In the studies by Schuzhu et al. and Mouravas et al., UCFs were developed $3.1 \%$ and $4.16 \%$ in the G-TIP compared with $3 \%$ and $8.7 \%$ in the C-TIP group $[6,12]$.

In terms of the glans dehiscence, the current study reported two cases of glans dehiscence (3.7\%) developed in the G-TIP group compared with no cases in the C-TIP group. These were corrected using C-TIP urethroplasty after 6 months of the primary repair. Other studies reported glans dehiscence as well where two cases $(6.7 \%)$ of partial glans dehiscence were reported in G-TIP group of Helmy et al. study [14], and $4.16 \%$ versus $4.35 \%$ developed glans dehiscence were reported in the G-TIP and C-TIP groups of Mouravas et al. study [12].

This study included three cases $(5.5 \%)$ of distal penile hypospadias with mild chordee who underwent G-TIP repair with excellent overall results except for residual minimal to mild postoperative chordee. In Gupta et al. study, seven cases (2.6\%) developed residual postoperative chordee and they explained this by the hypothesis that the graft uptake might have been associated with development of hypergranulation and possible vertical graft contracture which may have been a contributory factor for the development of residual chordee in long inlay grafts as the study included both distal and proximal cases [13]. 
In terms of the cosmetic outcomes, the HOSE score in the present study was comparable between the G-TIP and the C-TIP. These results were comparable to Shuzhu et al., study where HOSE score was 14.34 for C-TIP group with a success rate of $93.9 \%(180 / 198)$ compared with a HOSE score of 14.25 for G-TIP with a success rate of $92.5 \%$ (148/160) [6]. Despite being statistically insignificant, results of this study showed potentially better clinical results in favor of the G-TIP. We refer this to the skin graft that provides epithelialized urethral plate from the beginning, and this might contribute to decreasing the fibrosis reaction which occurs after dorsal incision of the urethral plate in the classic repair.

One limitation that must be acknowledged in this study is the relatively short follow-up compared to other series. However, most of the complications of hypospadias develop early postoperatively. Furthermore, we did not track blood loss for our patients intraoperatively because it is usually minimal, but none of the cases experienced noticeable bleeding.

\section{Conclusion}

The G-TIP urethroplasty provided comparable cosmoses, success rates and complications compared with C-TIP, and was accompanied with longer operative time.

\section{Abbreviations \\ C-TIP: Classic tubularized incised plate; FET: Fisher's exact test; G-TIP: Grafted tubularized incised plate; HOSE: Hypospadias objective scoring evaluation; TGD: Transverse glanular diameter; TIP: Tubularized incised plate; UP: Urethral plate; UCF: Urethro-cutaneous fistula.}

\section{Acknowledgements}

None.

\section{Authors' contributions}

SA participated in the study conception, surgery, data collection, and manuscript writing. YAN participated in revising data integrity and analysis, and manuscript revision and editing. HS contributed to the study conception, surgery, and manuscript writing. AZ participated in the study conception, data collection and analysis, follow-up of patients and manuscript writing. $\mathrm{RO}$ contributed to data collection, surgery, and manuscript editing. All authors read and approved the final manuscript.

\section{Funding}

None.

\section{Availability of data and materials}

The datasets used and/or analyzed during the current study available from the corresponding author on reasonable request.

\section{Declarations}

\section{Ethics approval and consent to participate}

This study was conducted according to the Declaration of Helsinki for medical research on humans and after obtaining local ethics approval from
Ethics Committee at Benha Faculty of Medicine (REC: IDIRB2017122601) and informed written consent to participate in this study was obtained from all participants' parents/legal guardians for all children under 16 years old.

\section{Consent for publication}

Not applicable.

\section{Competing interests}

The authors declare that they have no competing interests.

\section{Author details}

${ }^{1}$ Department of Urology, Faculty of Medicine, Benha University, Benha 13511, Egypt. ${ }^{2}$ Division of Urology, King Abdulaziz Medical City, Riyadh, Saudi Arabia.

Received: 6 July 2021 Accepted: 29 October 2021

Published online: 22 November 2021

\section{References}

1. Snodgrass W (1994) Tubularized, incised plate urethroplasty for distal hypospadias. J Urol 151:464-465

2. Braga LH, Lorenzo AJ, Salle JL (2008) Tubularized incised plate urethroplasty for distal hypospadias: a literature review. Indian J Urol 24:219-225

3. Eliçevik M, Tireli G, Sander S (2004) Tubularized incised plate urethroplasty: 5 years' experience. Eur Urol 46:655-659

4. Kolon TF, Gonzales ET Jr (2000) The dorsal inlay graft for hypospadias repair. J Urol 163:1941-1943

5. Holland AJA, Smith GHH, Ross Fl, Cass DT (2001) HOSE: an objective scoring system for evaluating the result of hypospadius surgery. BJU Int 88:255-258

6. Shuzu C, Min W, Yidong L, Weijing Y (2016) Selecting the right method for hypospadias repair to achieve optimal results for the primary situation. Springer Plus 5:1624

7. Lopes JF, Schned A, Ellsworth PI, Cendron M (2001) Histological analysis of urethral healing after tubularized incised plate urethroplasty. J Urol 166(3):1014-1017

8. Perera M, Jones B, O'Brien M, Hutson JM (2012) Long-term urethral function measured by uroflowmetry after hypospadias surgery: comparison with an age matched control. J Urol 188:1457-1462

9. Schwentner C, Seibold J, Colleselli D, Alloussi SH, Schilling D, Stenzl A (2011) Single-stage dorsal inlay full-thickness genital skin grafts for hypospadias reoperations: extended follow up. J Pediatr Urol 7(1):65-71

10. Abbas TO, Pippi Salle JL (2018) When to graft the incised plate during TIP repair? A suggested algorithm that may help in the decision-making process. Front Pediatr 6:326

11. Asanuma H, Satoh H, Shishido S (2007) Dorsal inlay graft urethroplasty for primary hypospadiac repair. Int J Urol 14:43-47

12. Mouravas V, Filippopoulos A, Sfoungaris D (2014) Urethral plate grafting improves the results of tubularized incised plate urethroplasty in primary hypospadias. J Pediatr Urol 10:463-468

13. Gupta V, Yadav SK, Alanzi T, Amer I, Salah M, Ahmed M (2016) Grafted tubularised incised plate urethroplasty: an objective assessment of outcome with lessons learnt from surgical experience with 263 cases. Arab J Urol 14(4):299-304

14. Helmy TE, Ghanem W, Orban H, Omar H, El-Kenawy M, Hafez AT, Dawaba M (2018) Does grafted tubularized incised plate improve the outcome after repair of primary distal hypospadias: a prospective randomized study? J Pediatr Surg 53(8):1461-1463

\section{Publisher's Note}

Springer Nature remains neutral with regard to jurisdictional claims in published maps and institutional affiliations. 